\title{
The impact of information technology on productivity using structural equations technique in Iran Behnoush Company
}

\author{
Yaser Ghorbanzad $^{\mathrm{a}^{*}}$ and Mina Beig ${ }^{\mathrm{b}}$
}

\begin{abstract}
${ }^{a}$ Master of Industrial Management(OR), Department of Management and Economy, Science and Research Branch, Islamic Azad University, Tehran, Iran ${ }^{b}$ Master of Industrial Management(OM), Department of Human Science, Najafabad Branch, Islamic Azad University, Isfahan, Iran

\begin{tabular}{l}
\hline A R T I C L E I N F O \\
\hline Article history: \\
Received October 1, 2011 \\
Received in Revised form \\
November, 14, 2011 \\
Accepted 15 February 2012 \\
Available online \\
2 March 2012 \\
\hline Keywords: \\
Productivity \\
Information technology \\
Structural equations technique
\end{tabular}
A B S T R A C T

Information technology plays an important role on increasing productivity in many organizations. The primary objective of the present survey is to study the impact of information technology on productivity and find a positive and significant relationship between these two factors. Structural equations technique and LISREL software are used for analysis of the questionnaires distributed among managers and some employees of Iran Behnoush Company. Organizations try to improve their performance by investment in information technology. However, many of the previous studies indicate insignificance of the impact of information technology on productivity of the organizations. The present survey studies the impact of information technology on organizations' productivity through the collected data from the above company. Results confirm existence of a positive relationship between information technology and productivity.
\end{abstract}

\section{Introduction}

Today, information technology (IT) is advancing rapidly and studies at an extensive level try to establish a better perception of attributes of productivity growth especially multi-attribute growth of productivity. Machines with high quality (more advanced) create more capital services (in the efficiency unit) than older equipments. One of the conducted studies in this regard illustrates that there is a direct relationship between investment in advanced technology and applying human force with high skills. In addition, such studies reveal that there are strong relationships among various actions of the organization and information technology attributes. They show that information technology, organizational actions and interaction of these two have positive impacts on productivity. Black and Lynch (2004) applied such data to study the impacts of accepting work environment actions and using computer on productivity.

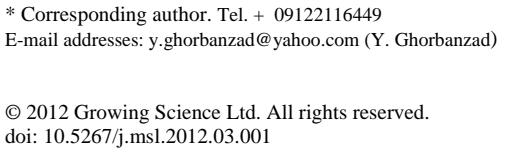


They understood that changes of work environment actions play important roles in productivity enhancement by increasing of computer application. During the past two decades, there have been tremendous efforts to understand how recent advances of IT could influences productivity of organizations. Anderson (1989) used structural equation model to examine the effects of the implementation of information systems for workers. He used a system of five structural equations to study the causal relationships between the characteristics of workers, jobs, and systems, which could be accounted for the satisfaction and utilization of information technologies by nonsupervisory workers. Anderson reported that the character of the job and the individual worker have negligible influence on the ultimate satisfaction and usage of CBIS by workers, while education and training in the system and opportunities for enhanced work productivity were relatively more important.

Sohn and Moon (2003) used structural equation model for predicting technology commercialization success index (TCSI). They implemented a structural equation model (SEM) to predict the TCSI associated with technology developer and receiver, technology transfer center, and environmental factors. The proposed SEM was fitted based on partial least square (PLS) estimation procedure and independent TCSI was used for American customer satisfaction index (ACSI) for different combinations of characteristics of the mentioned items. They expected that the proposed approach for TCSI could be implemented as guidance for an ideal match of technology with technology developer and technology receiver.

Lee et al. (2011) investigated the impact of service R\&D on the performance of Korean information communication technology small and medium enterprises. Lin (2009) investigated the business value of information technology as measured by technical efficiency. Their results indicated that IT spending had not been able to increase technical efficiencies of individual countries and that given technological changes, the so-called productivity paradox could exist in a country, no matter whether it is a developed or developing nation.

Lin and Chiang (2011) studied the impacts of country characteristics on information technology as measured by productive efficiency. They investigated information technology (IT) contribution at a country level by linking it to the complementarity/substitutability phenomena created by the presence of IT and the five national characteristics. The results indicated that the IT productivity paradox happens in not only developing countries but also developed countries. Based on their results, Eastern European countries could gain more productive efficiency than the G7 countries when IT was considered as a production factor.

This survey intends to study the impact of information technology on productivity and decisionmaking process in the organization by using the collected data from Iran Behnoush Company. In the present survey, first theoretical principles of experimental studies are reviewed, then process of designing and data analysis are introduced. Finally, findings and the obtained conclusions will be represented.

\section{Theoretical principles of research}

Using information technology eliminates time and place limitations and it leads to economic growth and social equality and provides the possibility to represent services to deprived areas. There are several factors influencing IT and some of them are as follows,

- Human being: human resources, concepts and thought, innovation

- Mechanism: rules, regulations and methods, mechanisms for improvement and growth, financial and valuation mechanisms

- Tools: software, hardware, network and communications

- Structure: organizational, the related extra-organizational, global 
Information technology is composed of four major elements of human being, mechanism, tools and structure so that information in this technology is flowed through the value chain that is created by joining of such elements and its purpose is excellence and perfection of the organization. Previous studies defined productivity as the production level in lieu of a certain amount of input. Therefore, productivity is increased when lower amount of input is used at a stable production level or production level is enhanced with input stability. There are literally various advantages associated with increasing productivity such as cost reduction, enhancement of desirability and utility in terms of having better quality products, etc.

The role of information technology in revitalization of economic growth experienced in many developed industrial companies became more important by both academicians and policy-makers groups in the second half of the 1990's. Such technologies directly impact in advancement of economic growth. Information technology is important economically for two reasons according to the European Association Committee (2001). First, it makes acceptance of innovation and organizational changes very easily in factories. Second, they change competition status and structure of the market especially added competition arising from lower obstacles and creating new policies to deliver productions and services. In viewpoint of information technology economists have performed the highest search and examination during the two recent decades regarding the economic reaction of investment from this kind of technology (Badescu \& Garcés-Ayerbe, 2009).

Zein et al. (2005) investigated the relationship between information technology acceptance and organizational agility in Malaysia. They tried to find out the relationships between IT acceptance and organizational agility and try to understand how the acceptance of technology contributes to a firm's ability to be an agile competitor. They used Structural equation modeling techniques to analyze the data and their finding indicated that a survey involving 329 managers and executives in manufacturing firms in Malaysia indicated that actual system or technology usage had the strongest direct impact on organizational agility.

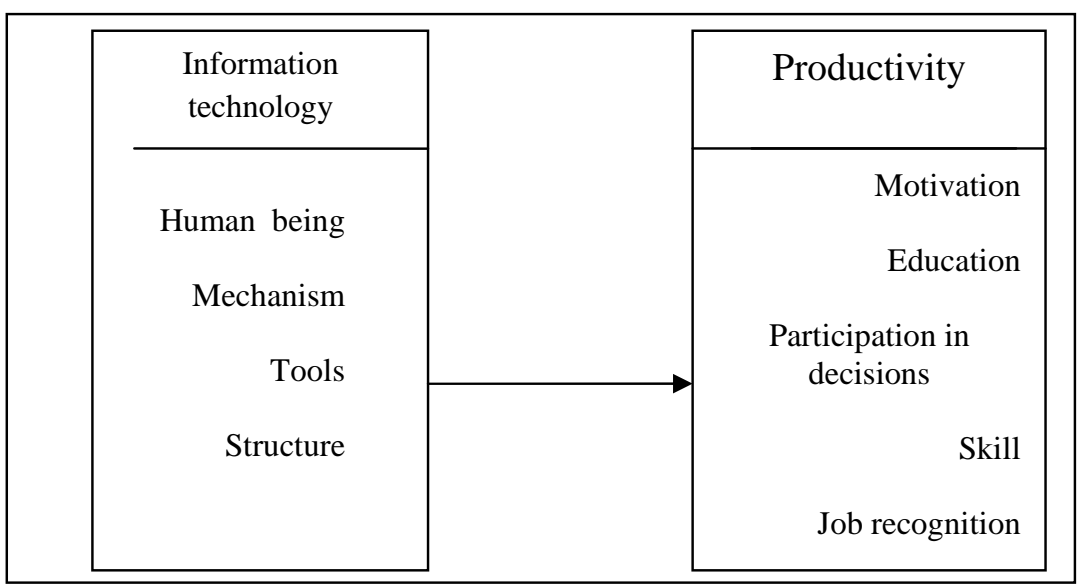

Fig. 1. Conceptual model

Boothby et al. (2010) have used such data to study the impacts of accepting work environment actions and computer application on productivity. They found out that changes of work environment actions along with increasing computer application have significant roles in productivity enhancement. As it was mentioned in previous section, the present survey emphasizes the impact of modern technology acceptance on the company's productivity. Here there are several reasons to 
emphasize evaluation of the company's productivity instead of using alternative attributes like profitability as profit variable.

First is that productivity of the company is obtained directly by changes in the production process. Second is that impact of technology acceptance on productivity could be easier than its impact on profitability (Fuentelsaz et al., 2009). Fig. 1 shows details of the relationship between productivity and information technology.

The primary question of this survey is whether IT influence productivity, significantly and how it could impact the proposed case study of this paper, Iran Behnoush Company.

\section{Research methodology}

The present survey is of applied type given to purpose and is of descriptive-correlation type with structural equations model given to the manner of data collection.

\subsection{Statistical population, sample and sampling method}

The intended statistical population for this survey is Iran Behnoush Company. Given to the obtained information 10 managers, 39 supervisors at various levels and 470 workers are working in this company. Such information has been summarized in Table 1 by separating organizational ranks.

\section{Table 1}

The necessary information associated with the statistical population of Iran Behnoush Company

\begin{tabular}{llll}
\hline Unit & Manager & Supervisor & Workers \\
\hline Processing & 1 & 1 & 10 \\
Packing & 1 & 11 & 130 \\
Quality control and development plan & 1 & 2 & 32 \\
Technical affairs & 1 & 4 & 12 \\
Properties affairs & 1 & 3 & 24 \\
Financial affairs and IT & 1 & 4 & 21 \\
Sales affairs & 1 & 12 & 190 \\
Public relations and market development & 1 & 2 & 15 \\
General management & 1 & social secretary & 1 \\
\hline
\end{tabular}

Kukran formula is used to determine number of sample volume given to the volume of statistical population that is equal to five-hundred twenty (520) people including managers, supervisors and workers.

$n=\frac{N t^{2} s^{2}}{N d^{2}+t^{2} s^{2}}$

where

$\mathrm{t}=$ percentage of standard error of the accepted coefficient of determination

$\mathrm{d}=$ confidence level or favorable probable precision

$\mathrm{s}=$ ratio of the population without a certain feature

$\mathrm{N}=$ number of people in the society

Number of the estimated sample from employees is equal to one-hundred twenty (120) persons using this formula. Simple random sampling method has been used in the present survey given to volume of the statistical sample. 


\subsection{Research tools}

Questionnaire is the measurement tool in this survey. It consists of twenty eight questions based on Likert five-option scale. Reliability and validity of the questionnaire have been calculated using Cronbach alpha and confirmatory factorial analysis.

\subsection{Data analysis method}

Structural equations technique was used to analyze the impact of human resources functions on organizational performance. Features $X^{2} / \mathrm{df}$, RMSEA, GFI, CFI and AGFI were applied to evaluate the intended model. Index $X^{2} / \mathrm{df}$ doesn't have a fixed attribute for an acceptable model but small amount of it indicates better goodness of the model (Azar, 2003; Hooman, 2009). If the amount of this ratio is between 2 and 3, it would be acceptable and whatever the ratio is smaller, the goodness of the model is better. Thus, the amount of 0.54 shows suitable goodness of the model in this survey. RMSEA index is equal to 0.05 or lower for good models. Higher amounts up to 0.08 show a reasonable error for approximation in the society. Models in which RMSEA is equal to 0.10 or more have a weak goodness. Goodness of fit index (GFI) and Adjusted Goodness of fit index (AGFI) show that the model has better goodness to what extent with regard to its nonexistence. Based on convention amounts of GFI, AGFI and CFI should be equal to 0.90 or higher so that the intended model would be accepted (Hooman, H.A, 2009)

\section{Research findings}

As it could be observed in Fig. 2 variables of motivation, education, customer-orientation, participation and job recognition are subcategory of the hidden variable, i.e. productivity and variables of human being, mechanism, tools and structure are subcategory of hidden variable of organizational performance. Research variables were analyzed based on the compiled conceptual model in LISREL software.

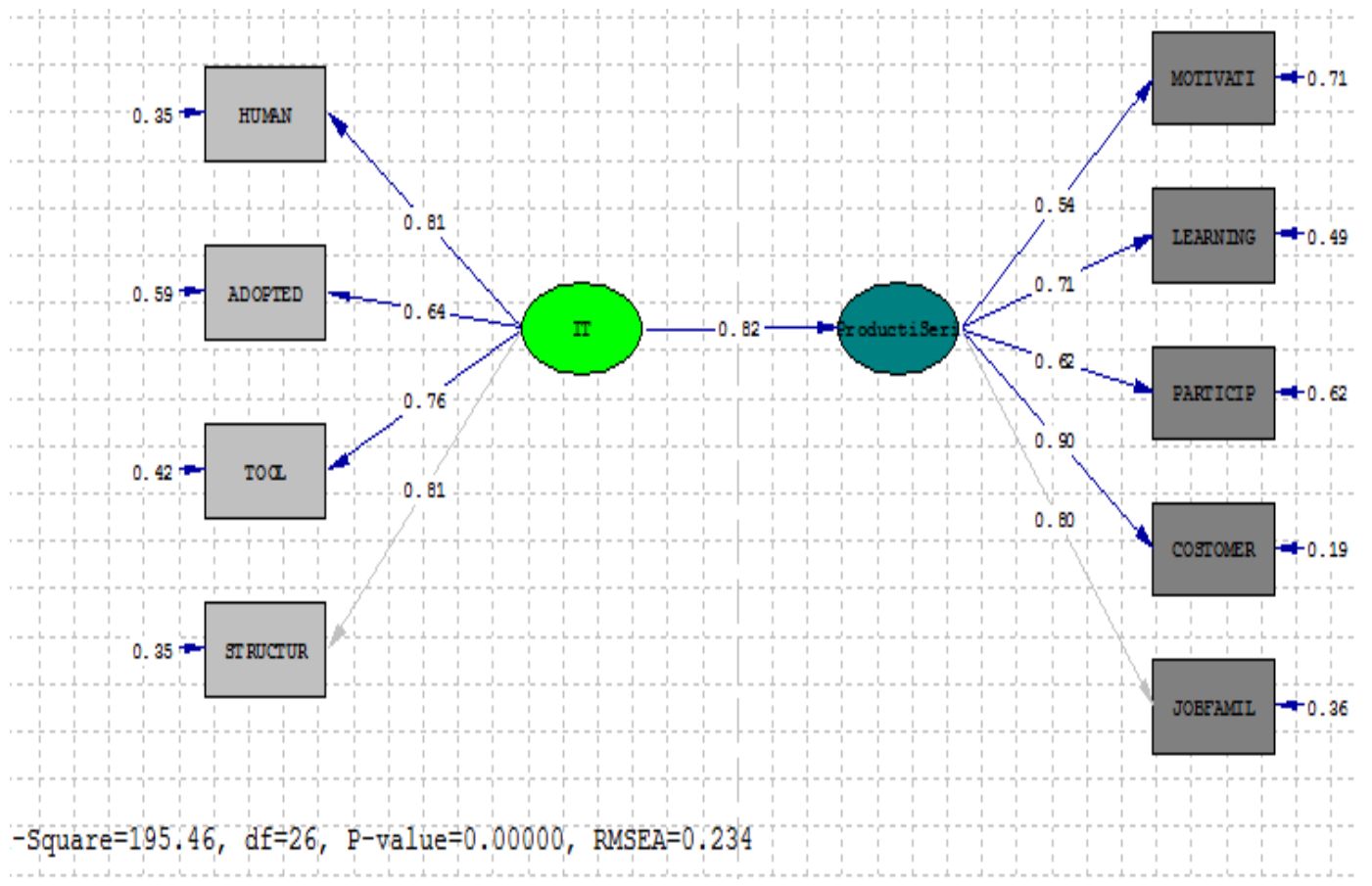

Fig. 2. Path diagram of human resources functions and organizational performance LISRELl model in Iran Behnoush Company 
Goodness indexes of the model (Table 2), i.e. $X^{2} / \mathrm{df}$, RMSEA, GFI, CFI and AGFI reveal that this model does not provide suitable goodness given to the output.

Table 2

features of the model's goodness

\begin{tabular}{lllll}
\hline $\mathrm{x} / \mathrm{df}$ & RMSEA & CFI & GFI & AGFI \\
\hline 7.51 & 0.23 & 0.78 & 0.73 & 0.54 \\
\hline
\end{tabular}

RMSEA index is equal to 0.05 or lower for good models. Higher amounts up to 0.08 show a reasonable error for approximation in the society. Models in which RMSEA is equal to 0.10 or more have a weak goodness. However, amount of RMSEA in this model is higher than the accepted amount. Based on convention amounts of GFI and AGFI should be equal to 0.90 or higher so that the intended model would be accepted (Azar, 2003). Therefore, the model of estimated indexes in Table 2 indicates weak goodness of the model. Recommended reformations by LISREL software were considered for better goodness of the model. Fig. 3 shows re-estimation of the model by considering the conducted reformations.

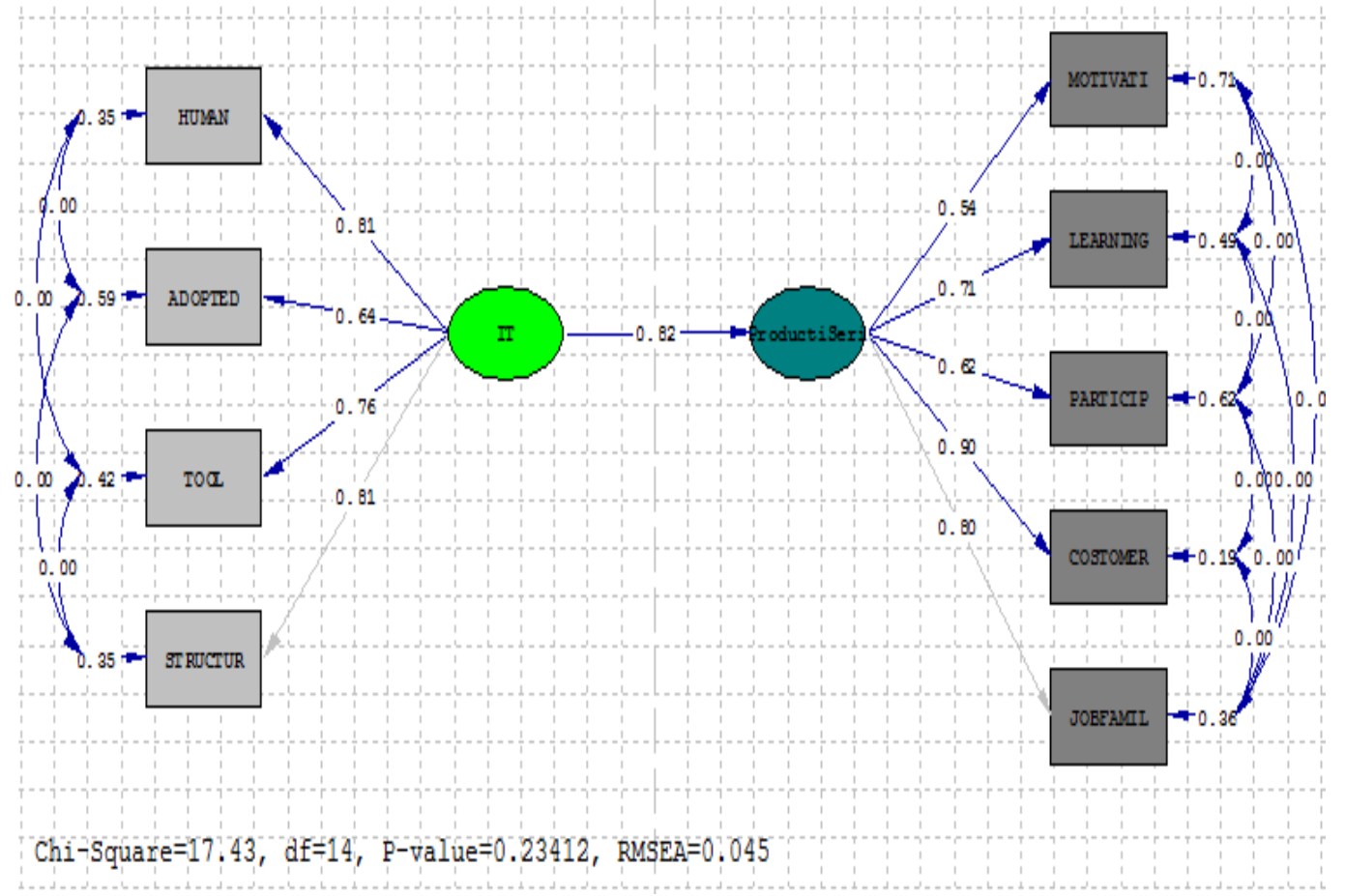

Fig. 3. Reformed model of path diagram

Factorial loads and explained variance of each component of human activities and organizational performance have been estimated. Results of this estimation are illustrated in Table 3 for components of productivity activities.

\section{Table 3}

Factorial loads and common estimated variance of components related to human resources activities

\begin{tabular}{|c|c|c|c|c|c|}
\hline $\begin{array}{l}\text { Components } \\
\text { productivity }\end{array}$ & $\begin{array}{l}\text { Factorial } \\
\text { load }\end{array}$ & $\begin{array}{l}\text { Explained } \\
\text { variance }\end{array}$ & $\begin{array}{l}\text { Components of } \\
\text { information technology }\end{array}$ & $\begin{array}{l}\text { Factorial } \\
\text { load }\end{array}$ & $\begin{array}{l}\text { Explained } \\
\text { variance }\end{array}$ \\
\hline Motivation & 0.54 & 0.68 & Human being & 0.62 & 0.42 \\
\hline Education & 0.71 & 0.39 & Mechanism & 0.73 & 0.50 \\
\hline Participation & 0.62 & 0.45 & Tools & 0.69 & 0.52 \\
\hline Customer orientation & 0.90 & 0.67 & Structure & 0.89 & 0.65 \\
\hline Job recognition & 0.80 & 0.41 & & & \\
\hline
\end{tabular}


Results of Table 3 reveal that customer-orientation component with factorial load equal to 0.90 and explained variance equal to 0.67 has more relative importance than other components. Factorial loads of all components are significant, statistically. Component of structure with factorial load equal to 0.89 and explained variance equal to 0.65 has more relative importance than other components. Also, explained variance of human being, mechanism, tools and structure components is equal to 0.42 , 0.50. 0.52 and 0.65, respectively. Factorial loads of all components are significant, statistically. Finally, direct impact of information technology on productivity is equal to 0.82 according to Fig. 2 and this amount is significant statistically $(\mathrm{p}<0.5)$. Goodness indexes of the model, i.e. $X^{2} / \mathrm{df}$, RMSEA, GFI, CFI and AGFI illustrate that this model has a suitable goodness by re-estimation of the model (Table 4), since GFI, CFI and AGFI indexes are more than 0.9 and RMSEA index is at a relative acceptable level.

\section{Table 4}

Goodness features of the model

\begin{tabular}{lllll}
\hline $\mathbf{x} / \mathbf{d f}$ & RMSEA & CFI & GFI & AGFI \\
\hline 1.24 & 0.045 & 0.99 & 0.97 & .90 \\
\hline
\end{tabular}

\section{Conclusion and recommendations}

If an organization wants to enhance productivity, it can use several methods. Information technology as an effective variable on two above factors, i.e. decentralization from decision-making process and improvement of business processes could increase productivity in the organization. Results of this survey reveal that information technology acts as a moderator variable, which increases productivity through decentralization from decision-making process and improvement of business processes. Results indicate that impact of business process improvement and decentralization from decisionmaking process on productivity in institutions in which investment in their information technology is relatively high and is more than those with investment in low information technology. Information technology is affected by several factors and each one could have a positive and indirect impact on performance of the organization and finally productivity (human, mechanism, tools and structure). As a result, information technology does not have a direct impact on productivity of the organization necessarily; rather it enhances performance of the organization through decentralization from decision-making process and improvement of business processes.

\section{References}

Anderson, E.E. (1989).The implementation of information systems for workers: A structural equation model. Information \& Management, 16(4), 171-186

Azar, A. (2003). Path analysis and causation in management science. Journal of Qom Higher Education Institute, 4(15), winter.

Badescu, M., \& Garcés-Ayerbe, C. (2009). The impact of information technologies on firm productivity: Empirical evidence from Spain. Technovation, 29, 122-129.

Boothby, D., \& Dufour, A. (2010). Technology adoption, training and productivity performance. Jianmin Tang Research Policy, 39, 650-661.

Feldstein, M. (2003). Why is productivity growing faster? Journal of Policy Modeling 25, 445-451.

Fuentelsaz, L., Gómez, J., \& Palomas, S. (2009). The effects of new technologies on productivity: An intrafirm diffusion-based assessment. Research Policy, 38(7), 1172-1180.

Hooman, H.A. (2009). Structural equations model by using LISREL software. Tehran: SAMT publications.

Lin, W.T. (2009).The business value of information technology as measured by technical efficiency: Evidence from country-level data. Decision Support Systems, 46(4), 865-874. 
Lee, Y., Kim, S., \& Lee, H. (2011).The impact of service R\&D on the performance of Korean information communication technology small and medium enterprises. Journal of Engineering and Technology Management, 28(1-2), 77-92.

Lin, W.T., \& Chiang, C.Y. (2011). The impacts of country characteristics upon the value of information technology as measured by productive efficiency. International Journal of Production Economics, 132(1), 13-33.

Poon, S.K., Davis, J.G., \& Choi, B. (2009). Augmenting productivity analysis with data mining: An application on IT business value. Expert Systems with Applications, 36, 2213-2224

Sohn, S.Y., \& Moon, T.H. (2003). Structural equation model for predicting technology commercialization success index (TCSI). Technological Forecasting and Social Change, 70(9), 885-899.

Zain, M., Che Rose, R., Abdullah, I., \& Masrom, M. (2005).The relationship between information technology acceptance and organizational agility in Malaysia. Information \& Management, 42(6), 829-839 